\title{
A Cloud-based Virtual Computing Laboratory for Teaching Computer Networks
}

\author{
Razvan I. Dinita, Member, IEEE, George Wilson, Adrian Winckles, Marcian Cirstea, Senior Member, IEEE, Aled \\ Jones \\ Anglia Ruskin University, Cambridge, UK \\ razvan.dinita@anglia.ac.uk, george.wilson@anglia.ac.uk, adrian.winckles@anglia.ac.uk, marcian.cirstea@anglia.ac.uk, \\ aled.jones@,anglia.ac.uk
}

\begin{abstract}
This paper presents a novel 'Cloud-based' solution for teaching computer networks in an educational context. One key advantage of the system is its ability to comission and decomission virtual infrastructures comprised of routers, switches and virtual machines on demand. It makes use of hardware located in different physical locations, VMWare software to manage the virtual resources and NetLab+ to manage the configuration of multiple different virtual scenarios. The key features of the cloud infrastructure are described and evaluated.
\end{abstract}

\section{INTRODUCTION}

Nowadays, students are increasingly attracted to computers, the internet and all networking involved in fully exploiting the increasingly larger computing resources available through the internet. Students are coming with a wide variety of technical and cultural background, motivation, age, experience and learning styles and all of these must be taken into account either by course extension in order to establish a common foundation, or by lecturers in higher education adapting their expectations and the programmes they offer.

As the first method normally requires extra resources, such as extra teaching staff hours, availability of rooms, technical support, etc., it is the last one which is normally preferred because it is cost and time effective [1]. Therefore, the necessity arises to reconsider the teaching and learning strategies, and to adapt them to the learning styles and constraints of modern university environments.

Cloud computing is an emerging technology that devolves computing resources to the Internet [2]. The traditional teaching of computer networking in a higher educational institution is very much dependent on local hardware resources. The student experience of different computer networks will often be limited to the local hardware infrastructure currently available. That architecture cannot be easily changed because of the resource issues involved.

At the university the authors are affiliated with, there are multiple IT infrastructures and software solutions put in place that aim to assist and provide study platforms for students. A few examples are the VLE (Virtual Learning Environment) built using Microsoft products, Moodle (Modular ObjectOriented Dynamic Learning Environment), which is an open source platform, WebCT (Course Tools) etc. However, all these systems only provide basic means of interaction such as file sharing, discussion boards, questionnaires, blogs and access to course materials. These systems lack the means to allow students to conduct experiments, test taught theories and create innovative applications in the context of their chosen modules.

This paper focuses on presenting a cloud-computing solution for teaching computer networks, in which the network teaching resource is itself virtualised. A similar approach has already been researched [3], having a proven track record with over $80 \%$ positive student feedback. This paper aims to pick up where that solution left off and take it one step further through development of the underlying infrastructure and expansion of the overlying software platform.

This kind of solution is not meant to replace the traditional hands-on student experience, but rather provide a useful and cost-effective supplementary educational tool to support the teaching of computer networks (including by distance learning).

There have been other similar attempts at using NetLab + in an Academic context as illustrated and described by [4], [5] and [6]. Although the software solutions used are similar, the test bed it has been deployed on makes the solution proposed by the authors of this paper a novel approach, which allows for implementation and testing of complex networking and security scenarios.

There have even been other similar attempts using clusters of Virtual Machines (VMs) [7] to virtualise automation learning topics based on the Moodle platform. The issue with that approach was that it was put together using multiple bits of technologies which could potentially allow a number of security breaches. It is also quite difficult to maintain, when it comes to expanding the infrastructure by adding more VMs or updating the Moodle platform.

Another virtual learning implementation was attempted by the authors of [8] through the implementation of four different virtual environments, each specialised in a different area of control-engineering. It makes use of a mix of open source Linux software and Matlab licensed software to provide the students with the means to implement and test different scenarios. Again, this kind of solution is difficult to maintain since it makes use of completely different software packages which have not been specifically designed to work together. 
TABLE I

TEST BED COMPRISING HARDWARE

\begin{tabular}{|c|c|c|}
\hline Make & Specifications & Quantity \\
\hline HP Proliant & $\begin{array}{l}\text { 108GB RAM } \\
2 x \text { Intel Six-Core Xeon } 2.4 \mathrm{GHz} \\
10 \text { Gbit NICs }\end{array}$ & 4 \\
\hline Dell R710 & $\begin{array}{l}38 \mathrm{~GB} \text { RAM } \\
2 \mathrm{x} \text { Intel Quad-Core Xeon } 2.4 \mathrm{GHz} \\
\text { Gbit NICs }\end{array}$ & 2 \\
\hline Viglen & $\begin{array}{l}\text { 16GB RAM } \\
\text { 2x Intel Dual-Core Xeon } 2.2 \mathrm{GHz} \\
\text { Gbit NICs }\end{array}$ & 1 \\
\hline HP Filer & $\begin{array}{l}8 \mathrm{~TB} \text { HDD } \\
10 \text { Gbit NICs }\end{array}$ & 1 \\
\hline $\begin{array}{l}\text { Dell Storage } \\
\text { Area } \\
\text { Network }\end{array}$ & $1.5 \mathrm{~TB}$ & 3 \\
\hline $\begin{array}{l}\text { HP } \\
\text { Integrated } \\
\text { Lights Out }\end{array}$ & Gbit NICs & 4 \\
\hline $\begin{array}{ll}\text { Cisco } 4948 \\
\text { Switch }\end{array}$ & Gbit NICs & 1 \\
\hline $\begin{array}{ll}\text { Cisco } 3560 \\
\text { Switch }\end{array}$ & Gbit NICs & 1 \\
\hline $\begin{array}{l}\text { Cisco } 5510 \\
\text { Adaptive } \\
\text { Security } \\
\text { Appliance } \\
\text { (ASA) }\end{array}$ & Gbit NICs & 1 \\
\hline NetLab Pod & N/A, proprietary appliance & 4 \\
\hline
\end{tabular}

\section{OBJECtives In A PEDAgOgicAl Theory CONTEXT}

From a business perspective there are three well-known technologies associated with Cloud Computing, namely Software-as-a-Service (SaaS), Platform-as-a-Service (PaaS) and Infrastructure-as-a-Service (IaaS). The current research aims to promote another cloud service technology in providing an educational resource that will focus on delivery of simulated network hardware resources (the concept of Laboratory-as-as-Service (LaaS)). This distinguishes the work from traditional virtual learning environments in common use in educational establishments today.

The development of this lab setup is taking into account Kolb's well established descriptive model of the Adult learning process, consisting of four stages [9]: Concrete Experience is followed by Reflective Observation which generates Abstract Conceptualisation; this leads to Active Experimentation which will generate a new Concrete Experience. Abstract Conceptualisation can be stimulated better in lecture sessions, addressing the cognitive type of objectives (such as memory, interpretation) in accordance with Bloom's taxonomy [10].

On the other hand, the Active Experimentation, Concrete Experience and Reflective Observation are better addressed in interactive laboratory sessions, which concentrate more on the other cognitive components identified by Bloom (Translation, Application, Analysis, Evaluation) and the Affective aspects of learning (Responding, Valuing and Organization in particular).
The paper is presenting research work which led to a new teaching and learning method that addresses this second aspect, by the development of a novel style Laboratory setup, based on cloud computing, providing a modern educational resource.

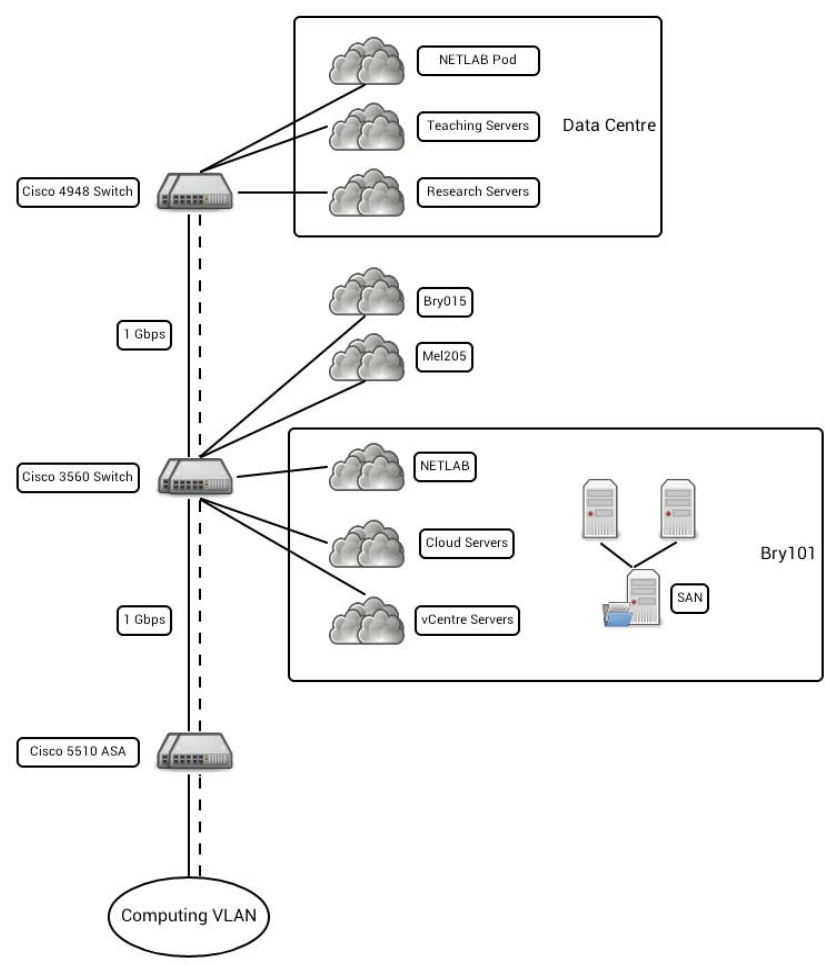

Fig. 1. Cloud Computing Test Bed - custom design and built infrastructure.

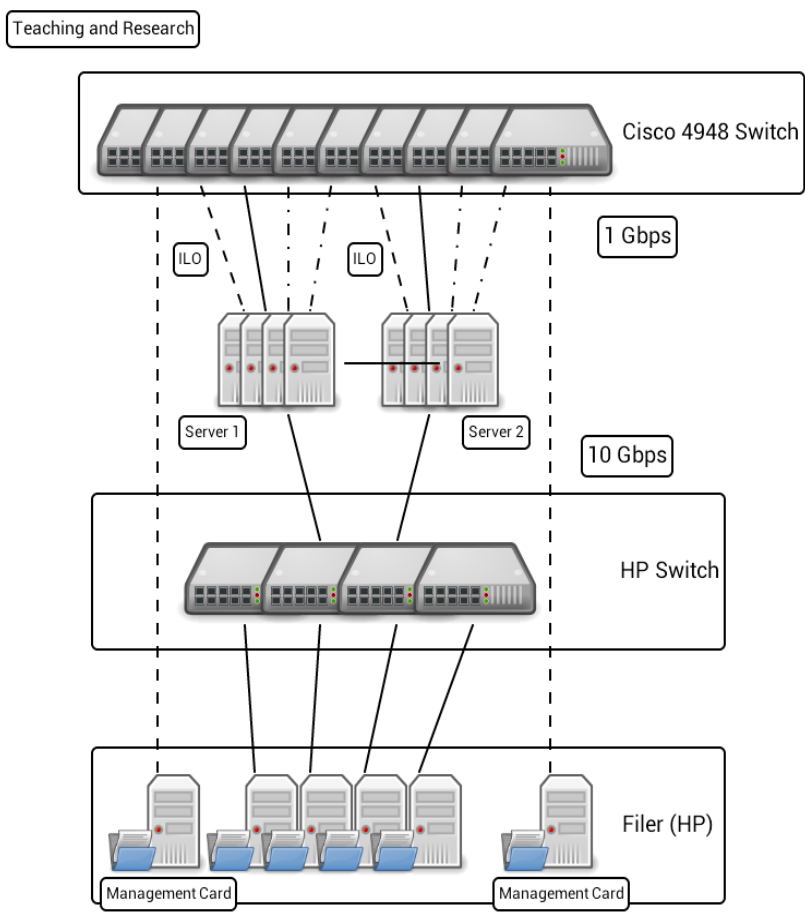

Fig. 2. Cloud Computing Test Bed - Datacentre view. 


\section{METHODOLOGY}

\section{A. Hardware Infrastructure}

The authors currently have a small but powerful test bed comprising seven physical servers (mix of HP Proliant, Dell R710 and Viglen brands), three Storage Area Networks (HP) and multiple routers and switches (CISCO and HP), and HP ILOs (Table I) located within the Department of Computing and Technology (Figs. 1 and 2 are illustrating the structure of these systems) across four rooms (Bry015, Mel205, Data Center, Bry101).

Two of the servers are 'public'-facing (that is, they are utilised for teaching purposes), whilst the others are 'private'facing (i.e. they are utilised for research - not yet implemented). The private-facing resource is isolated from the Internet and only accessible from departmental computers via an appropriate security protocol. All of the networking cards have Gigabit type interfaces $(>=1 \mathrm{Gbps}$, Gigabit per second, transfer rate) and the link between the Servers and the Filer (Fig. 2) is one of $10 \mathrm{Gbps}$, which facilitates rapid data movement to and from the Filer across the network.

The described test bed allows for the possibility of testing unique and complex scenarios such as simulating a global infrastructure, where each room is considered to be a remote location in a different country/part of the world.

\section{B. Software Administration}

Both commercially available and Open Source software is used to manage both the underlying physical network infrastructure and the virtualized appliances running on that physical network.

The Test Bed resource is currently being developed in two ways:

i) Proprietary off-the-shelf remote laboratory systems such as NDG's NetLab are being used to offer complex IT systems (such as VMware vSphere/vCentre/ESXi courses) which can be easily deployed as virtual based solutions on demand (solution currently fully implemented).

ii) Configuration of an Open Source Apache Virtual Computing Laboratory (VCL) in a network distributed environment to support commissioning of reusable operating resources, as described by Vouk [11]. This provides a cloud computing based solution for network security laboratory teaching scenarios (solution still in development).

VMWare products such as the ESXi Hypervisor and vCentre are used to manage the physical infrastructure and run the VMs, while NDG's NetLab+ software is used to manage virtual appliances ranging from simple VMs to CISCO Routers and Switches, commissioning them on demand.

The reasoning behind choosing VMWare and NDG's proprietary software is that they have a proven track record of performing well and exceeding expectations in academic environments. According to [3] the majority of students responded very positive to the virtual labs they had the opportunity of installing, configuring and managing. They also believed that it has enhanced their learning experience through hand-on virtual sessions using said software solutions.

\section{NDG's NetLab+}

$\mathrm{NetLab}+$ is able to commission and decommission entire virtual laboratories containing any number and combination of simple VMs, Routers and Switches (Fig. 3, 4, 5). This makes it an ideal environment for testing a great range of scenarios from simple networking to complex security configurations.

$\mathrm{NetLab}+$ gives access to the virtual resources based on username/password combinations assigned by the Administrator account. These are made available to students on different network and security modules as needed.

One key advantage of this solution is instant access and high availability at any hour of the day, account holders being able to connect to NetLab+ via the public Computing VLAN (Fig. 1).

The Computing VLAN provides public access to numerous internal services and other networks, including the proposed virtual infrastructure. The front-end server makes use of several NICs to interconnect the various internal networks. The internal networks have the following IP classes: 169.x.x.x for NetLab+, 10.141.x.x for the VMWare solution and 10.x.x.x for the rest of the university services (VLE, Moodle, eVision etc.). Each individual network makes use of its own authentication framework, almost all of which allow login using a single university set of credentials handed out to every student and staff member.

Once authenticated, the students can proceed to reserve a Lab session (Fig. 6), choosing one of the many available virtual configurations (Fig. 3, 4, 5).

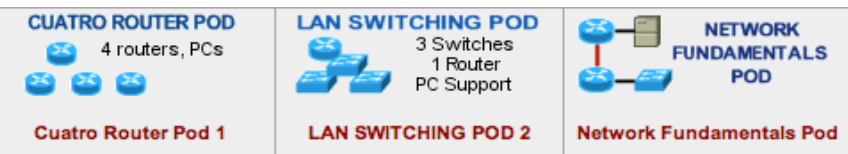

Fig. 3. NetLab+ Lab setups: 4 Routers, PCs; 3 Switches, 1 Router, PCs; Network Fundamentals setup (2 Routers, 1 Switch, PCs).

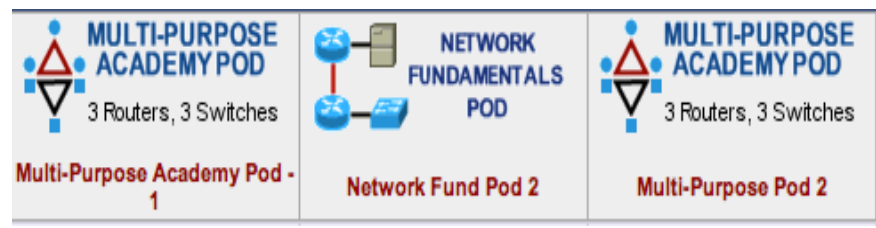

Fig. 4. NetLab+ Lab setups: 3 Routers, 3 Switches; Network Fundamentals setup (2 Routers, 1 Switch, PCs).

\begin{tabular}{|c|c|c|}
\hline $\begin{array}{l}\text { (a) M } \\
\text { I뭉뭉 ICM POD }\end{array}$ & $\begin{array}{l}\text { Monware } \\
\text { 뭄뭉 IcM POD }\end{array}$ & 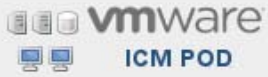 \\
\hline ICM Master Pod & VMware ICM Pod 1 & VMware ICM Pod 2 \\
\hline
\end{tabular}

Fig. 5.NetLab+ Lab setups: ICM (Install, Configure, Manage) Master and Standard Pods.

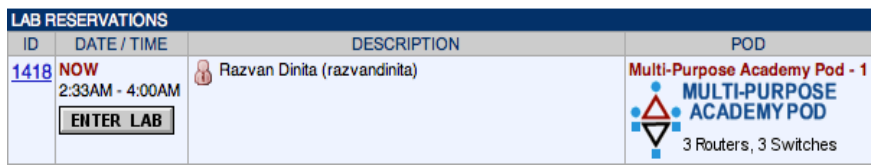

Fig. 6. NetLab+ reservation of a virtual Multi-purpose Academy Pod. 


\begin{tabular}{|c|c|c|c|}
\hline System & Web Browser & Version & Status \\
\hline \multirow{4}{*}{ \&y Windows } & (3) Mozilla Firefox & 3.6 .15 & Supported \\
\hline & Internet Explorer & 8.0.6 & Supported \\
\hline & (-) Apple Safari & 5.0 .2 & Beta \\
\hline & (2) Google Chrome & 7.0 .517 & Beta \\
\hline \multirow{2}{*}{ Mac } & Mozilla Firefox & 3.6 .15 & Supported \\
\hline & (-) Apple Safari & 5.0 .2 & Beta \\
\hline$\Delta$ Linux & Mozilla Firefox & 3.6 .15 & Supported \\
\hline
\end{tabular}

Fig. 7. NetLab+ web browser support.

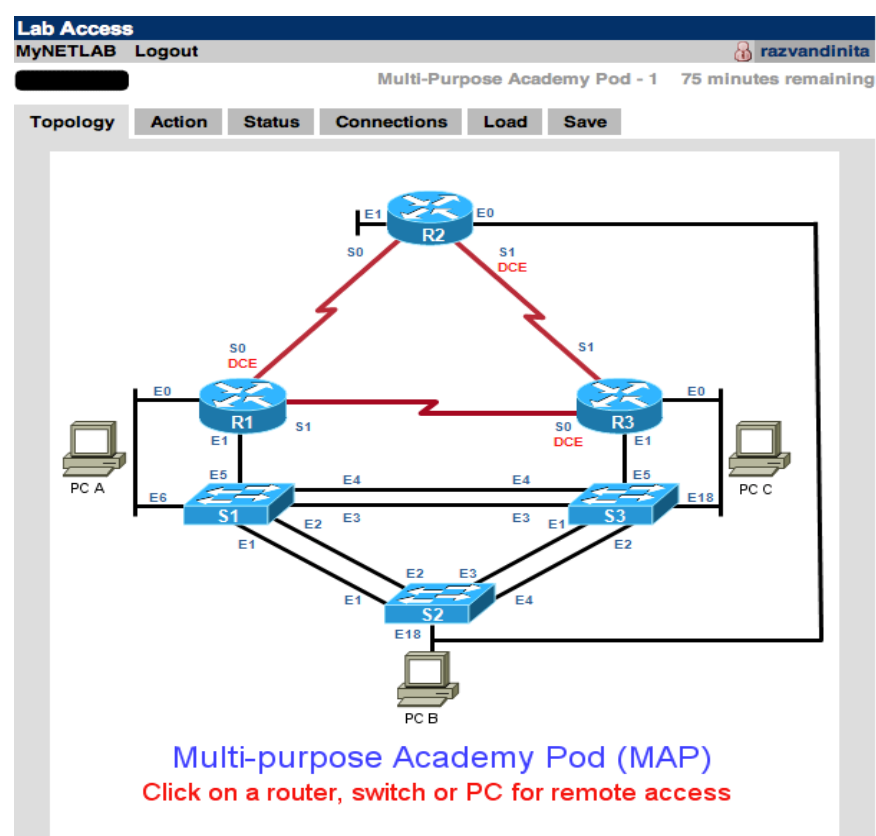

Fig. 8. Layout of a NetLab+ virtual Multi-purpose Academy Pod.

Many of the popular browsers (Fig. 7) can be used to fully interact with any part of the commissioned Virtual Lab setup. It makes heavy use of JavaVM to offer a rich GUI interface which allows easy management and configuration of any of the virtual appliances. For example the user can simply click $\mathrm{R} 1 / 2 / 3$ or $\mathrm{S} 1 / 2 / 3$ or $\mathrm{PC} \mathrm{A} / \mathrm{B} / \mathrm{C}$ (Fig. 8) to bring up a completely interactive Console Window.

Every Lab configuration also offers the possibility of either remembering changes made each session or running fresh configurations every time. It even allows easy export of configuration progress at any time during its operation.

- CCNA Exploration 1 - Network Fundamentals

- CCNA Exploration 2 - Routing Protocols and Concepts

- CCNA Exploration 3 - Switching and Wireless

- CCNA Exploration 4 - Accessing the WAN

- CCNA Exploration V4.0 CCNA 1 Network Fundamentals

- CCNA Security V1

- CCNA Security v1.1

- CCNP - BSI Building Scalable Internetworks - V5.0

- CCNP - BSMN - Builing Switched Multimedia Networks - V5.0

- CCNP - ICSW- Implementing Secure Converged Wide Area Networks - V5.0 - CCNP - Optimising Converged Networks - V5.0

Fig. 9. NetLab+ available Labs.

\begin{tabular}{|c|c|c|c|c|c|c|}
\hline CLASS NAME & LEAD INSTRUCTOR( & NROLL & START & END DA & LABS & B HOURS \\
\hline - Commercial CCNA (L T Fellowship) & $\begin{array}{l}\text { Adrian Winckles } \\
\text { Chris Holmes }\end{array}$ & 5 & None & None & 0 & 0.0 \\
\hline - Computer Network Principles 2009-10 Cam & $\begin{array}{l}\text { Adrian Winckles } \\
\text { Chris Holmes } \\
\text { Peter Cousins }\end{array}$ & 36 & None & None & 556 & 1113.5 \\
\hline - Computer Network Principles 2010-11 Cam & $\begin{array}{l}\text { Adrian Winckles } \\
\text { Chris Holmes } \\
\text { Ed Deacon }\end{array}$ & 66 & None & None & 63 & 128.0 \\
\hline - Computer Network Principles 2011-12 Cam & $\begin{array}{l}\text { Adrian Winckles } \\
\text { Chris Holmes } \\
\text { Ed Deacon }\end{array}$ & 69 & None & None & 18 & 19.4 \\
\hline O EJ315013S Network Management 2011 & $\begin{array}{l}\text { Adrian Winckles } \\
\text { Chris Holmes }\end{array}$ & 14 & None & None & 32 & 53.4 \\
\hline O Internet and Network Security Cam 2011 & $\begin{array}{l}\text { Adrian Winckles } \\
\text { Chris Holmes }\end{array}$ & 16 & None & None & 110 & 257.1 \\
\hline - IT Infrastructures Cambidge 2011 & $\begin{array}{l}\text { Adrian Winckles } \\
\text { Chris Holmes }\end{array}$ & 28 & None & None & 42 & 73.8 \\
\hline O Miscellaneous 2010 & $\begin{array}{l}\text { Adrian Winckles } \\
\text { Chris Holmes }\end{array}$ & 19 & None & None & 71 & 108.8 \\
\hline O Network Fundamentals ILM 2012 & $\begin{array}{l}\text { Adrian Winckles } \\
\text { Chris Holmes }\end{array}$ & 2 & None & None & 0 & 0.0 \\
\hline - Standard Class & $\begin{array}{l}\text { Adrian Winckles } \\
\text { Chris Holmes }\end{array}$ & 2 & None & None & 6 & 6.0 \\
\hline 0 VMware Demo Training Class & $\begin{array}{l}\text { Adrian Winckles } \\
\text { Chris Holmes } \\
\text { Peter Cousins }\end{array}$ & 11 & None & None & 2 & 2.1 \\
\hline \multicolumn{6}{|c|}{ Total $90 \mathrm{C}$} & 1762.1 \\
\hline
\end{tabular}

Fig. 10. NetLab + module classes with instructors, number of enrolled students and number of Labs and Lab Hours completed.

\section{RESULTS}

Since there are a large number of Labs (training courses and materials) available as part of the NetLab+ solution, students have been granted access to the NetLab + setup from the very beginning of its first deployment on the previously described test bed. Students enrolled on a wide variety of Network and Security modules have been testing the setup and at the same time learning how to install, configure and manage a wide range of Cisco appliances.

As it can be seen in Fig. 10, there already have been 900 Labs and over 1700 hours of lab work put into testing the described NetLab+ solution by over 260 students, all of which have ran without any issues.

At university level, there is an academic process called Module Evaluation, which is a simple survey presented to enrolled students. This gives students the opportunity to comment anonymously on various aspects of their modules. Student feedback plays an important role in quality enhancement. The findings of these surveys informs of both successful and unsuccessful teaching and learning practices.

In current context, the students who took part in testing of the proposed virtual infrastructure were enlisted on the following modules: Computer Network Principles, Network Technologies and Network Management.

Recently, they have been presented with a Module Evaluation survey for each of the mentioned modules. The survey results have exceeded all expectations, as almost all students believe that they have had their study experience enhanced by the proposed virtual infrastructure.

The students, however, have expressed several ideas for improvement:

- Better mobile access. Currently, since the NetLab+ solution is written almost entirely in Java there is almost no mobile support as of this writing. Of course, having better mobile access would increase 
student satisfaction levels as this would allow them to quickly login and check on projects running on commissioned VLabs, or simply continue a previously started Lab.

- Access to more physical networking hardware. Currently, there is only one rack containing networking hardware available to students to interact with. Having access to physical hardware allows students to better understand the Labs they have access to through much needed hand-on experience with cabling and configuring real-world networking equipment. This would ultimately improve their chances of getting employed once completing their course.

\section{FUTURE WORK}

Future work will involve development of the system administration of the Cloud Computing Test Bed, including:

- Expansion of the private-facing hardware (addition of more PCs - some are already available).

- Development of new software modules to manage disparate hardware and operating systems across a network

Currently, as already mentioned, only the teaching side solution of this proposed solution has been fully implemented. The authors will implement the research solution in due course, which will provide even more flexibility by supporting fully customised virtualised appliances to be deployed and tested.

One proposed use of the Test Bed will be to develop optimization software which would improve energy sustainable cloud based solutions. Such software would be capable of autonomous decision making based on hardware loads, ultimately perhaps resulting in the movement of VMs across the network, be it to another server in the local cluster or one located in a different geographical location.

\section{CONCLUSIONS}

Both VCL and NetLab + solutions are capable of delivering an automated and self-maintained virtualised remote computing environment to cater for students' need, with very little ongoing administration.
Whilst VCL provides a highly scalable, flexible and very cost effective solution, it is limited in terms of the complexity of the solutions potentially offered. NetLab + provides a more managed solution, better able to provide the complexity and flexibility that more advanced computer science courses may require, a premise supported by the setup shown in Fig. 10.

Also, in the long run, a NetLab+ setup will be easy to maintain and expand as NetLab+ has been specifically been designed to work with the VMWare vCentre/ESXi solutions, as opposed to using other virtualisation platforms alongside different open source software [7], [8].

\section{REFERENCES}

[1] Cirstea, M.N., (2003), "Problem Based Learning in Microelectronics", Int. Journal of Eng. Education, Vol. 19, No.5, 2003, pp.738-741, ISSN:0949-149X.

[2] Mirashe, S. P., and Kalyankar, N. V. (2010), "Cloud Computing," [Communications of the ACM], 51(7), 9.

[3] Winckles, A., Spasova, K., Rowsell, T. (2011), "Remote Laboratories and Reusable Learning Objects in a Distance Learning Context", Networks, Issue 14, January 2011.

[4] Prieto-Blázquez, J., Arnedo-Moreno, J., Herrera-Joancomartí, J. (2008), "An Integrated Structure for a Virtual Networking Laboratory", IEEE Transactions on Industrial Electronics, Vol. 55, No. 6, June 2008

[5] Kumar, K., Weiqing, S., Pratik, R., Tianning, L., Sekar, R. (2005), "VNetLab: A Cost-Effective Platform to Support Course Projects in Computer Security", 9th Annual Colloquium for Information Systems Security Education (CISSE 05), June 2005.

[6] Weiqing, S., Varun, K., Kumar, K., Sekar, R. (2008), "V-NetLab: an approach for realizing logically isolated networks for security experiments", Proceedings of the conference on Cyber security experimentation and test (CSET'08), USENIX Association, Berkeley, CA, USA, , Article 5, 6 pages.

[7] Vicente, A.G., Muñ, Oz, I.B., Galilea, J.L.L., del Toro, P.A.R. (2010), "Remote Automation Laboratory Using a Cluster of Virtual Machines", IEEE Trans. on Industrial Electronics, vol. 57, no. 10, pp. 3276 - 3283 , Oct 2010.

[8] Ramos-Paja, C.A., Scarpetta, J.M.R., Martinez-Salamero, L. (2010), "Integrated Learning Platform for Internet-Based Control-Engineering Education", IEEE Trans. on Industrial Electronics, vol. 57, no. 10, pp. 3284 - 3296, Oct 2010.

[9] Kolb, D.A. (1984), "Experiential Learning: experience as the source of learning and development", Prentice-Hall, New-Jersey.

[10] B. Bloom, (1956), "Taxonomy of Educational Objectives", Longmans Green, New York.

[11] Vouk, M. et al. (2009). "Using VCL Technology to implement distributed reconfigurable data centres and computational service for educational institutes", ACM Digital, [Online]. 